\title{
On Modelling the Reliability of Concrete Support for Underground Construction Considering the Impact of Chemical Erosion
}

\author{
Konstantin Golovin ${ }^{1}$, Roman Kovalev ${ }^{1}$, and Andrey Kopylov ${ }^{1, *}$ \\ ${ }^{1}$ Tula State University, 30001290 Lenin av., Tula, Russia
}

\begin{abstract}
Ensuring the reliability of support in mine workings has always been one of the most important scientific and technical problems in mining. To ensure the normal operation of underground structures, it is necessary to apply special measures to maintain the support, providing increased stability of rock array. To one of the most important measures is to maintain the reliability of the supports in underground workings and objects of underground construction. The main method of research in this area is the modeling of the reliability of concrete support, as applied to various exogenous and endogenous factors of disturbance. The article provides theoretical provisions of research in physico-chemical processes of corrosion in reinforced concrete for modelling the reliability of structural elements of supports for underground construction objects.
\end{abstract}

\section{Introduction}

Prediction of the durability of reinforced concrete structures on the territory of Russian Federation is carried out according to Federal Standard 2.03.11-85 "Protection of building structures against corrosion." However, in this document there is no regulatory methodology for assessing the durability of reinforced concrete structures in mines, which is associated with the complexity of the physico-chemical processes of corrosion of concrete and the unreliability of predicting the parameters of the underground operating environment. The most convenient design model for use in mining engineering calculations is one of the results of numerous studies in the field of predicting the durability of concrete or reinforced concrete, namely, the calculated dependence of the depth of corrosion damage on the time of operation of the structure $L=f(t)[1]$.

The durability of the reinforced concrete structure under the corrosive effects of the external environment can be conventionally represented as a combination of two periods ( $T$ $=t_{1}+t_{2}$ ) [2], which is graphically illustrated in Fig. 1:

However, in fact, as the durability $T$, it is advisable to consider only the term $\mathrm{t}_{1}$, (before the start of corrosion of the reinforcement), that means neglecting the term $t_{2}$, since the error in determining the term $t_{2}$ can be very large. It is the approach that is used by most researchers, although attempts to determine the $t_{2}$ term more or less reliably have already been made.

\footnotetext{
*Corresponding author: toolart@mail.ru
} 


\section{Materials and Methods}

Up to date, there are no standard design methods for calculation the term $t_{l}$, which determines the relevance of research in this area. Indeed, the dependence of the depth of damage should be the basis for decision-making, both in the design of new mines and in the resource assessment of the concrete structures in operation. Since the existence of reinforced concrete is possible only if there is a protective layer $a_{z}$ and adhesion of reinforcement to concrete, it is most convenient to determine the term $t_{l}$ by the functional dependence of the depth of damage $L=f(t)$, based on the condition $L<a_{z}[3]$.

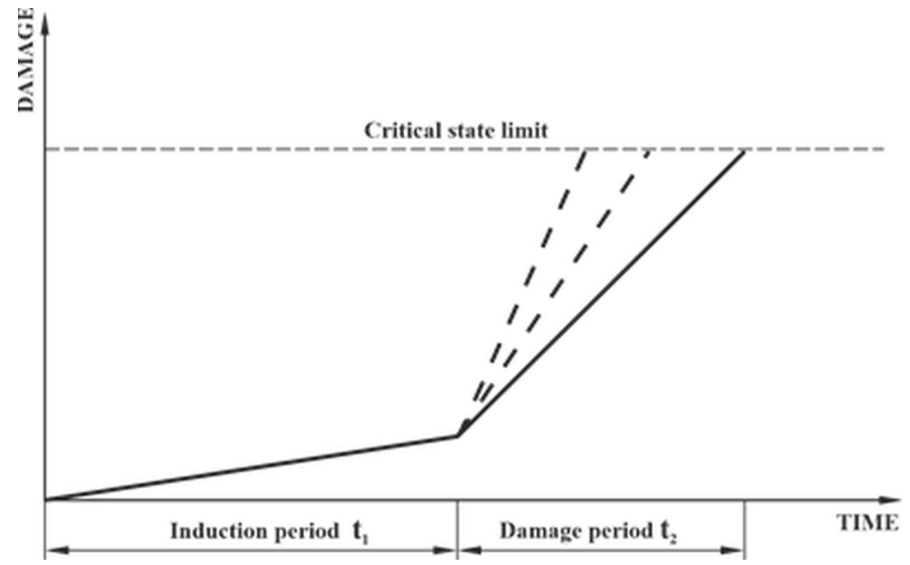

Fig. 1. Scheme of corrosion damage to the steel in the concrete.

The classical solution, based on the simplification of the mathematical apparatus and the schematization of physical-and-chemical processes of corrosion of concrete, has the form of reinforced concrete in the field of durable concrete "the law of the square root of time" [4]:

$$
L=K \sqrt{t}
$$

The analysis of modern provisions for improving the design models of the durability of reinforced concrete shows the almost complete absence of formulas that are convenient for mining engineering calculations. However, the construction of a mathematical model of corrosion of reinforced concrete to obtain the regularity $L=f(t)$ using modern numerical methods implemented in applied mathematical software packages allowed the authors A.R. Anvarov and T.V. Latypova get the expression (2) with the exponent $n$ with the root equal to 3 (3) [5-6]. It should be noted that in this case the nature of the aggressive environment was not considered (gas or liquid), and the solution was to obtain a general form of the calculated dependence $L(i)$. To take into account the peculiarities of the environment by above mentioned authors, it was proposed to use the coefficients of working conditions $m_{i}$ in the calculation formula.

$$
\begin{aligned}
& L=m_{i} A \sqrt[n]{t} \\
& L=m_{i} A \sqrt[3]{t}
\end{aligned}
$$

To confirm, refute or optimize the calculated models, the series of experimental points are required. However, due to the long duration of the experiments (regardless of the type of aggressive environment), the majority of researchers obtained dependence on only one 
experimental point (the dependence of depth of corrosion damage from time) or, in a rare case, on two points obtained as a result of a survey of reinforced concrete structures, and for further calculations took a dependence in the form of (1) [7].

Dividing the design scheme for determining the corrosion depth of concrete into zones of "interpolation" and "extrapolation", an important practical conclusion can be made about the field of application of equations with the power index of $1 / 2$ or $1 / n$ [8]. In the "interpolation" zone, the right boundary of which can be an experimental point with a relatively short test period (less than $5 \ldots 8$ years), equations 1 and 2 are equally applicable, since the values of the experimental points can, with the same error, belong to the distributions of both. For the longer periods, the difference in the prediction of the corrosion depth indicated in the "extrapolation" zone becomes apparent (Fig. 3).

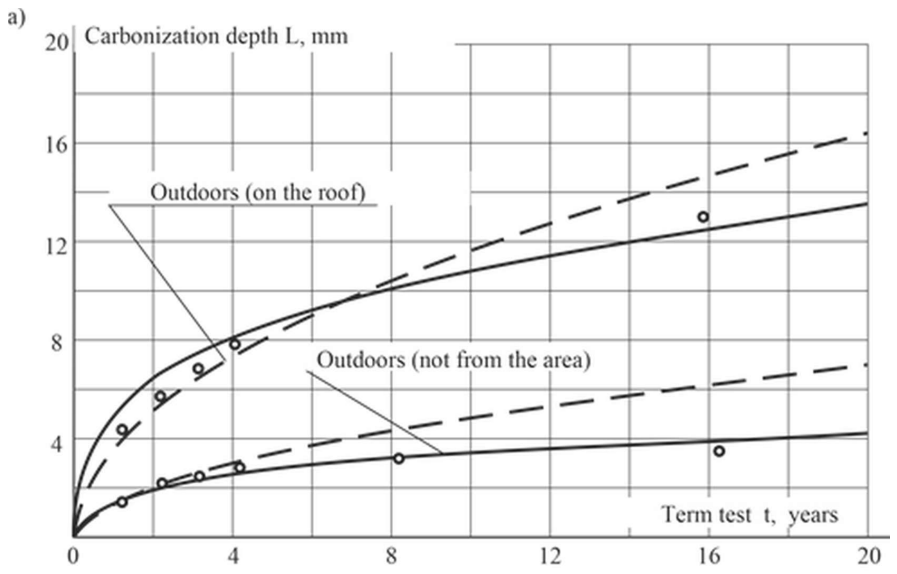

b)

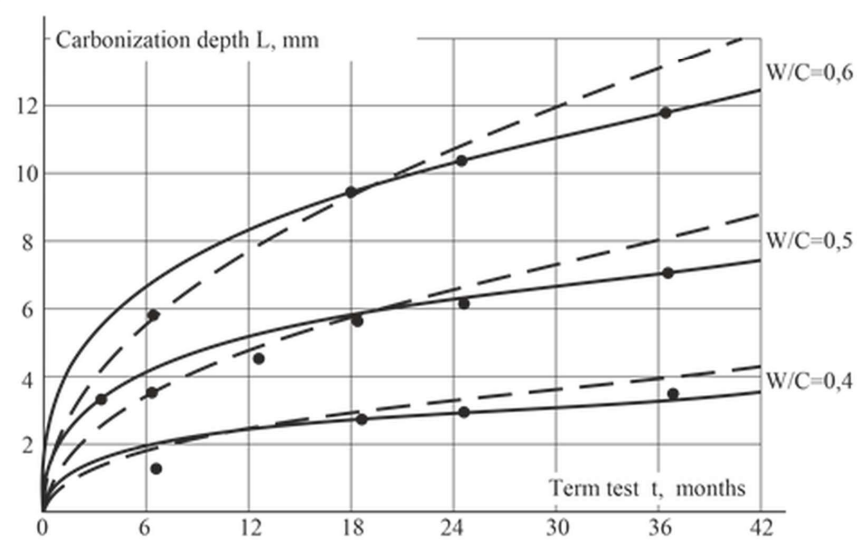

$$
\begin{aligned}
& \text { a) - average test results S.N. Alekseeva for } 27 \text { concretes } \\
& \text { b) - experimental data L.A. Vandalovskaya } \\
& \text { - envy of the species } \quad \mathrm{L}=\mathrm{K} * \sqrt{\mathrm{t}} \\
& \text { - envy of the species } \quad \mathrm{L}=\mathrm{A} * \sqrt[3]{\mathrm{t}}
\end{aligned}
$$

Fig. 2. Experimental data obtained by prof. S.N. Alekseev and L.A. Vandalovskaya.

The only known experimental data on several test periods on samples under natural conditions (when exposed to carbon dioxide in the air) are the data of L.A. Vandalovskaya for concretes with different water-cement ratio (W/C). From these data it follows that the exponent $n$ with the root can take values of $2.05 \ldots 3.05$. Researchers T. Isida and K. Maekawa 
provide experimental data on the neutralization depth of concrete with different water-cement ratios at $10 \% \mathrm{CO}_{2}$ concentration of carbon dioxide, from which it follows that the value of $n$ in the expression (2) varies within $1.94 \ldots 2.65$ [9]. In general, the analysis of few experimental data showed that the possible values of the exponent $n$ in expression (2) vary from 1.48 to 3.05 .

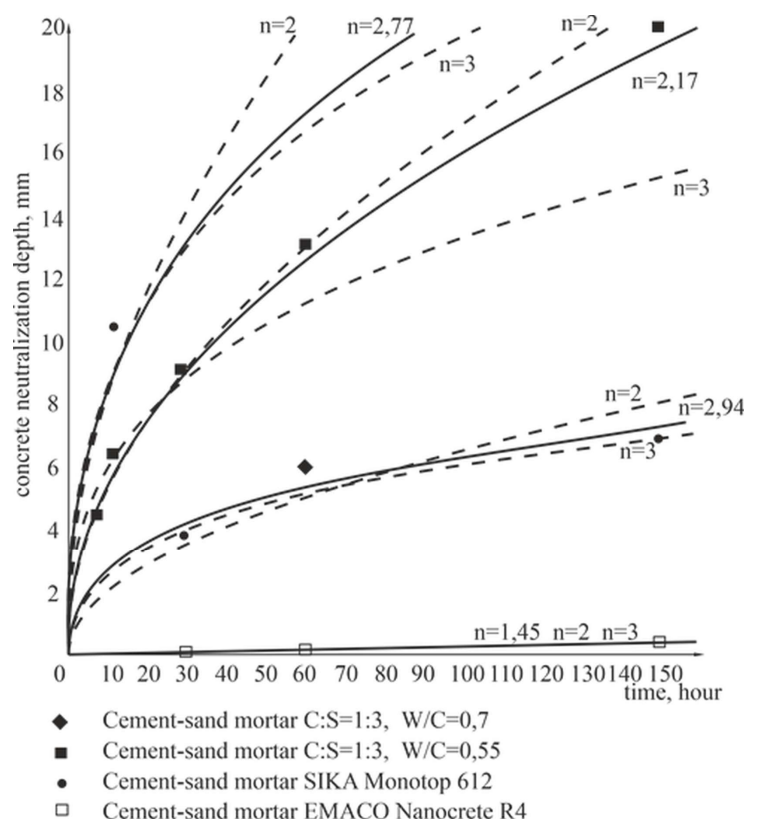

Fig. 2. Experimental data on the rate of neutralization of concrete obtained by P.A. Fedorov and B.R. Anvarov.

The examples of experimental results demonstrate the rate of neutralization of concrete in the natural conditions of air with different periods of operation. Tests or performance data for concretes working in liquid media conditions of modern mines are practically absent.

Due to the lack of publicly available experimental data when assessing the durability of reinforced concrete by means of the "square root-of-time law" when assessing the reliability of structures with a life span of more than 10 years is not inappropriate [10-11].

\section{Results and Discussion}

The ultimate goal of creating a mathematical model of corrosion $L=f(t)$ is to obtain a sufficiently simple calculation method applicable for mining engineering calculations with a high degree of confidence. Corrosion of concrete is associated with the interaction of polymineral cement stone with a multicomponent environment [12-14]. A mathematical model of physic-and-chemical interaction is a second-order differential equation in partial derivatives, which simultaneously takes into account diffusion, dissolution and chemical interaction of two components A (external environment) and B (in the case of concrete corrosion, these are soluble components of the cement stone) with "slow" or "fast" reaction Table 1, equation 1). 


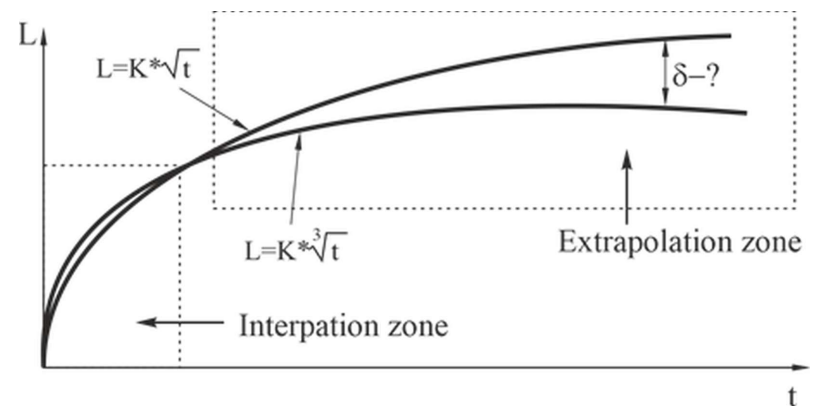

Fig. 4. The design scheme for determining the depth of corrosion of concrete after a given period of operation.

Or in the case of a simpler interaction - "the reaction does not proceed", the process is determined only by diffusion (Table 1 , equation 2 ), where:

$C_{i}$ - the concentration of the i-th substance;

$R_{i}$ - the function characterizing the speed of a component damaged per unit volume of the medium as a result of the reaction;

$D_{i}$ - effective diffusion coefficient;

$K_{B}$ - the rate constant of dissolution of the solid phase;

$S_{B}$ - the specific internal surface of the cement stone;

$P_{B}$ - concrete porosity.

The main problem in obtaining a simple method of calculation from the reduced system of equations is that the system of equations 4 of Table 1 does not have an analytical solution as in the case of the absence of a chemical reaction, equation 5 table 1 . Therefore, as a rule, the decision is made on equating $R_{i}(C)=0$, and thus actually go to equation 5 , Table 1 .

Table 1. The set of equations.

\begin{tabular}{|l|l|l|l|}
\hline $\begin{array}{c}\text { The } \\
\text { variant of } \\
\text { interaction } \\
\text { of } \\
\text { substances } \\
\text { A and B }\end{array}$ & $\begin{array}{c}\text { An example of } \\
\text { the interaction of } \\
\text { concrete with } \\
\text { diffusing } \\
\text { external } \\
\text { environment }\end{array}$ & Process description & Differential equation describing the process \\
\hline $\begin{array}{l}\text { Chemical } \\
\text { reaction } \\
\text { proceeds }\end{array}$ & $\begin{array}{l}\text { Contact of cement } \\
\text { stone with mortars } \\
\text { of salts }\end{array}$ & $\begin{array}{l}\text { The presence of } \\
\text { chemical interaction } \\
\text { of concrete with the } \\
\text { environment, the } \\
\text { process is controlled } \\
\text { by diffusion and } \\
\text { chemical reactions }\end{array}$ & $\frac{d C_{A}}{d t}=D_{A} \frac{d^{2} C_{A}}{d x^{2}}+R\left(C_{i}\right)$ \\
\hline $\begin{array}{l}\text { Chemical } \\
\text { reaction } \\
\text { does not } \\
\text { proceed }\end{array}$ & $\begin{array}{l}\text { Contact of cement } \\
\text { stone } \\
\text { chlorides }\end{array}$ & $\begin{array}{l}\text { Contact of cement } \\
\text { stone with chlorides }\end{array}$ & $\frac{d^{2} C_{B}}{d x^{2}}+\frac{K_{B} S_{B}}{P_{B}} \times\left(C_{B 0}-C_{B}\right)+R\left(C_{i}\right)$ \\
\hline
\end{tabular}

In modern conditions of computer technology development, it is possible to obtain a solution to the system of equation 4 in Table 1 using the modern apparatus of numerical methods implemented in packages of various mathematical programs.

In a second order chemical reaction, the system of equations 4 in Table 1 takes the form (6): 


$$
\begin{gathered}
\frac{d C_{A}}{d t}=D_{A}^{t} \frac{d^{2} C_{A}}{d x^{2}}-\mu k_{11} C_{A} C_{B} \\
\frac{d C_{B}}{d t}=D_{B}^{t} \frac{d^{2} C_{A}}{d x^{2}}+\frac{K_{B} S_{B}}{\Pi_{B}}\left(C_{B 0}-C_{B}\right)-\mu k_{11} C_{A} C_{B}
\end{gathered}
$$

where $k_{11}$ - the effective rate constant of a chemical reaction; $\mu$-stoichiometric coefficient of chemical reaction.

\section{Conclusion}

Solving the system of equations (6) using the apparatus of numerical methods, comparing the obtained data with experimental and operational ones will improve the accuracy of prediction of the reliability of reinforced concrete mining structures in the "extrapolation" zone, as well as provide an opportunity to evaluate the possibility and feasibility of reconstructing the object and applying secondary means of primary protection.

\section{References}

1. B. V. Gusev, Mathematical models of the processes of corrosion of concrete IPC (TIMR, Moscow, 1996)

2. L. M. Puhonto, Durability of reinforced concrete structures of engineering structures (Publishing House DIA, Moscow, 2004)

3. I. G. Ovchinnikov, V.V. Petrov. Mathematical modeling of the process of interaction of structural elements with aggressive media (SPI, Saratov, 1983)

4. V. V. Bolotin Methods of the theory of probability and the theory of reliability in the calculation of structures (Constructions Pub., Moscow, 1982)

5. P. A. Fedorov, B. R. Anvarov, T. V. Latypova, A. R. Anvarov, V. M. Latypov, Bulletin of the South Ural State University, 15:191, 13-15 (2010)

6. B. R. Anvarov, T. V. Latypova, V. M. Latypov, L. Ya. Kramar, News of higher educational institutions. Building, 2:674, 12-22 (2015)

7. A. B. Kopylov, V. S. Salnikov, O. V. Konovalov, L. E. Sheinkman, News of Tula State University. Earth Sciences, 1, 170-174 (2010)

8. S. V. Fedosov, V. E. Roumyantseva, I. V. Krasilnikov, B. E. Narmania, International Journal for Computational Civil and Structural Engineering, 13:2, 45-49 (2017)

9. J. R. Davis, Corrosion: Understanding the Basics (ASM International, Dover, 2000)

10. S. M. Haleem, S. Wanees, E. E. Aal, A. Diab, Corrosion Science, 52:5, 1675-1683 (2010)

11. M. C. Brown, R. E. Weyers, M. M. Sprinkel, ACI Materials Journal, 98:3, 240-250 (2001)

12. C. M. Hansson, Cement and Concrete Research, 14, 547-584 (1984)

13. Types and Causes of Concrete Deterioration (Portland Cement Association, Skokie, 2002)

14. A. M Neville, Properties of Concrete (Longman Group Limited, London, 1995) 